\title{
Review on Major Disease Threats in Case of Emergencies
}

Hylemariam Mihiretie ${ }^{1^{*}}$, and Asaye Birhanu ${ }^{2}$

${ }^{1}$ Department of Medical Laboratory Sciences, Wollega University, Nekemte, Ethiopia

${ }^{2}$ Department of Medical Laboratory Sciences, Addis Ababa University, Addis Aabab, Ethiopia

*Corresponding author: Hylemariam Mihiretie, Department of Medical Laboratory Sciences, Wollega University, Nekemte, Ethiopia, Tel: 251576617981; E-mail: hylemariam@gmail.com

Rec: Nov 14, 2016, Acc: Apr 10, 2017, Pub: Apr 14, 2017

Copyright: ( 2017 Mihiretie $\mathrm{H}$, et al. This is an open-access article distributed under the terms of the Creative Commons Attribution License, which permits unrestricted use, distribution, and reproduction in any medium, provided the original author and source are credited.

\begin{abstract}
Emergencies, caused by growth of world's population, affects weather conditions and cause outbreaks of several communicable diseases that result in high morbidity and mortality specially in developing countries. The cumulative effects of these disasters include displacement, increasing vector breeding sites, unplanned and overcrowded shelters, poor water and sanitation conditions, poor nutritional status and poor personal hygiene, low levels of immunity to vaccine-preventable diseases or insufficient vaccination coverage, and limited access to healthcare services.
\end{abstract}

Flooding is one of the commonest natural disasters which results in contamination of drinking-water facilities, facilitation of the transmission of water-borne diseases (typhoid fever, cholera, leptospirosis and hepatitis A) and vector-borne diseases (malaria, dengue and dengue hemorrhagic fever, yellow fever, and West Nile Fever).

Malaria is among the most important diseases that are aggravated by movement and migration. The transmission of malaria is strongly influenced by population movements and by the process of urbanization. Pneumonia is one of the diseases which is more prevalent in overcrowded and unprotected communities. Similarly, diarrhoea is aggravated by unhygienic lifestyles which is common in case of emergencies. Since the occurrence of emergencies and natural disasters is uncertain, every country should develop a way of preventing infectious disease that may occur in consequence of natural disasters, war and terrorism.

Keywords: Emergency; Disease threat

\section{Introduction}

With a substantial growth of natural disasters over the past years, there is an increasing outbreaks of infectious disease. Urbanization associated land shortage, population growth and poverty lead peoples to dwell in disaster prone areas. Natural disasters may kill people directly or indirectly by promoting the transmission of infectious diseases. Developed countries are also vulnerable to natural disasters as Hurricane Katrina in the USA (2005) and the Great Eastern Japan Earthquake and tsunami (2011) can be witnesses [1,2].

Rapid and slow-onset natural disasters such as floods, earthquakes, hurricanes and droughts occur globally every year because of adverse weather conditions or poor land use. Communicable diseases also account for most of the reported deaths among conflict-affected populations due to displacement, malnutrition and limited access to basic needs [3].

Natural and manmade disasters have a prolonged health impact. The collapse of health facilities and healthcare systems, disruption of surveillance and health programs, limitation or destruction of farming activities, interruption of ongoing treatments and use of un-prescribed medications may be secondary to natural disasters. The effects of disasters on the health care system include environmental changes, increasing vector breeding sites, high exposure to and proliferation of disease vectors, unplanned and overcrowded shelters, poor water and sanitation conditions, poor nutritional status and poor personal hygiene, low levels of immunity to vaccine-preventable diseases or insufficient vaccination coverage, and limited access to healthcare services. These effects can shift disease epidemiology and increase drug resistance, too [2].

Since there is ongoing population change and occurrence of disasters, the impact of infectious diseases may be more death trap in developing countries like Ethiopia where there is an increasing population and urbanization. There is a paucity of published data regarding disaster associated diseases in Ethiopia. We hereby tried to summarize diseases associated with flooding, war, migration, earthquake, displacement and bioterrorism. Therefore, the aim of this review is to point out the occurrence of infectious diseases associated with emergencies in the World with in the last a few decades.

\section{Diseases Associated with Flooding, Earthquake and Tsunami}

Researchers have been documenting that flood disasters are the most common natural disasters worldwide. According to studies flooding causes disease outbreak resulting from the displacement of people into overcrowded camps, cross contamination of water sources with fecal material and toxic chemicals and proliferation of mosquitoes resulting in an upsurge of mosquito-borne diseases such as malaria [2].

The major risk factor for outbreaks associated with flooding is the contamination of drinking-water facilities. Floods can potentially increase the transmission of the following communicable diseases: Water-borne diseases, such as typhoid fever, cholera, leptospirosis and 
hepatitis A and Vector-borne diseases, such as malaria, dengue and dengue hemorrhagic fever, yellow fever, and West Nile Fever [4]. One of the features of floodwater is that it is a hospitable breeding ground for pathogenic microorganisms that can cause disease. This group of illnesses is called waterborne diseases and is named as such because they are transmitted when a person ingests the contaminated water which includes Amoebiasis, Cyclosporiasis, Cryptosporidosis, and Giardiasis [1].

Diarrhoea out breaks was reported in many parts of Ethiopia following the occurrence of 2005 and 2006 floods in Gambella Region. The problem of diarrhoea was aggravated in temporary resettlement camp because of overcrowding and inadequate water and sanitation. Above all the risks of diarrhoea outbreak were high when displaced population returned to their villages. This was because the floods destroyed protected springs, shallow wells and boreholes [5].

According to Brown C et al. [6] 43\% of persons presented with an infectious disease, most commonly respiratory tract infections, sexually transmitted diseases, and soft tissue infections following 2010 Haiti earthquake. In addition, $30 \%$ of undifferentiated fevers were caused by falciparum malaria as reported [6]. According to public health surveillance conducted after the tsunami struck in 11 South Asian countries in 2004, the rate of diarrhoea was 2950 per 100, 000 populations [7].

\section{Diseases Associated with War and Bioterrorism}

War has devastating consequences, including death, displacement of people, and destruction of public infrastructure and physical and social capital. However, when the end of war represents the beginning of lasting peace, there are good reasons to believe that recovery is possible, albeit gradual [8].

After World War II, chronic diseases, cardiovascular diseases in particular, became a major public health problem in industrialized countries. These diseases were perceived as diseases of affluence. Finland was hit hard: in the 1960s, Finland had the world's highest rate of deaths from coronary heart disease. Middle-aged men were dying in great numbers. The rates were even higher in the east of the country the highest figures being in the Province of North Karelia [9].

Public health authorities should be vigilant to the potential for outbreaks deliberately caused by biological agents (bioterrorism). Diseases like Anthrax, Shigellosis, Salmonellosis, Brucellosis and others could occur due to bioterrorism [10]. War can be a source of unexplained symptoms including "soldier's heart," "shell shock," "effort syndrome," and "Gulf War syndrome." Similar illnesses characterized by unexplained symptoms include fibromyalgia, chronic fatigue syndrome, somatization disorder, and multiple chemical sensitivity [11].

The wars directly interfered with food production by, for example, preventing farmers from planting and harvesting on time and by reducing the labor force through coercive conscription. Looting by soldiers of peasants' property, particularly livestock and seeds, has been a traditional practice in Ethiopia. Diarrheal diseases resulted in high child mortality in war affected areas and refugee camps. Epidemics of both louse-borne typhus and relapsing fever have traditionally been associated with crowded army camps, as during the Ethic-Eritrean war, and crowded prisons and relief camps. A rapid increase in sexually transmitted diseases, above all AIDS, may prove to be the most devastating public health outcome of the war in the long term.
Prostitution and violence against women were common wherever the army operated. HIV infection and AIDS became epidemic in Ethiopia towards the end of the war [12].

\section{Diseases Associated with Drought and Over Crowding}

Waterborne diseases are spread when humans ingest contaminated water. Typhoid, cholera, hepatitis, and dysentery are the most common diseases resulting from animal and human waste contaminated water. Diarrheal diseases are also seen regularly and can be some of the most harmful. The symptoms and effects of diarrheal diseases can be fatal for those that already suffer from inadequate immune systems. WaterBased: Diseases are considered water-based when aquatic organisms transmit them. Worms can infect humans by penetrating the skin during a bath or be ingested in contaminated water. These worms cause schistosomiasis, which is the second deadliest parasitic disease only behind Malaria. Four in every five people infected with this disease are living within Sub-Saharan Africa [13].

A paper presented in South Africa reported that malaria has been identified as the most frequent cause of mortality and morbidity in many refugee camps like Cambodians in Thailand, Mozambicans in Malawi, and Ethiopians in eastern Sudan [14].

In early 1985, the measles-specific death rate among children under 5 in one eastern Sudan camp was 30 per 1000/month; the case-fatality rate (CFR) based on reported cases was almost 30\%. Large numbers of measles deaths have been reported in camps in Somalia, Bangladesh, Sudan, and Ethiopia. In Thailand (1979), Somalia (1980), Sudan (1985), Honduras (1986), and Malawi (1989), ARIs were cited among the three main causes of mortality in refugee camps, particularly among children. In one of the few refugee populations studied, the HIV prevalence among adult male Sudanese refugees in western Ethiopia in 1992 was 7\%; the prevalence of infection among commercial sex workers living in the vicinity of the camp was greater than $40 \%$ [15].

\section{Migration, Resettlement and Movement Associated Diseases}

The recent diffusion of Severe Acute Respiratory Syndrome-SARS, an atypical pneumonia of unknown etiology, is the latest example of the spread of a disease due to population movements. It is believed that the disease started in China, and in only six months it has already spread to 28 countries in all continents (mainly due to air travel), has infected 4,836 people, and has taken 293 lives. Malaria is among the most important diseases that are aggravated by movement and migration. The transmission of malaria is strongly influenced by population movements and by the process of urbanization. Whether malaria risk increases or decreases depends on the social, economic and behavioral characteristics of the migrants, on the type of ecological setting, on the availability of malaria vectors in the area, and on the changes people impose on the environment. Historical evidence, briefly discussed here, reveals that the onset and spread of epidemics of different diseases can be facilitated by both migration and urbanization. Most often, malaria increases in all newly opened frontiers for economic development in agriculture and mining, in those areas affected by war, lawlessness and open conflicts, and in locations that are a focal point for refugee migrations [14].

A study done in Amazon new settlement showed that malaria prevalence rates were higher in newly opened areas relative to old 
Citation: Mihiretie H, Birhanu A (2017) Review on Major Disease Threats in Case of Emergencies. J Med Microb Diagn 6: 253. doi:

settlements, ranging from $1 \%$ to $2 \%$ to $14 \%$ to $26 \%$, respectively [14]. A 20 years' study in Spain showed that diseases associated with immigration include filariasis, malaria, trypanosomiasis, cysticercosis, schistosomiasis, intestinal parasites, latent and active TB, acute and chronic infections with hepatotropic virus, sexually transmitted infections (STI), HIV infection, leprosy, respiratory tract infections, gastrointestinal bacterial infections, and urinary tract infections [16].

\section{Conclusion}

Major disease threats in case of emergencies like natural disasters (flooding, tsunami, earthquake, landslides, volcanic eruptions, droughts, famine and immigration) and wars and bioterrorism can be classified as water borne, vector borne, airborne and noncommunicable diseases. In general pneumonia, malaria, diarrhoea, and acute respiratory syndromes are the most common communicable diseases that occur in emergencies. Thus, it is recommended that the world should be take care of global warming and be ready to prevent emergencies. Besides that, every country should develop a way of preventing infectious disease that may occur in consequence of natural disasters, war and terrorism.

\section{Acknowledgments}

The authors would like to acknowledge Addis Ababa University who contribute for the reality of this review.

\section{Conflict of Interest}

The authors declare that no conflicts exist regarding the publication of this review.

\section{References}

1. Isidore K, Aljunid S (2012) Preventing and controlling infectious diseases after natural disasters. United Nations University.
2. Oshitani H, Hammad K, Kamigaki T, Aljunid S, Kouadio I (2012) Infectious diseases following natural disasters: prevention and control measures. Expert Rev Anti-Infect Ther 10: 95-104.

3. (2007) Control of Communicable Diseases in Emergencies. Public health guide for emergencies. American Red Cross Society 7:284-369

4. Flooding and Communicable Diseases: Risk assessment and preventive measures, Communicable Disease Working Group on Emergencies, WHO HQ 2005; 1-6

5. Abaya S (2008) Floods and Health in Gambella region, Ethiopia: An assessment of the strength and weakness of the coping mechanism. [Msc Thesis], Lund University, Sweden.

6. Brown C, Ripp J, Kazura J (2012) Perspectives on Haiti two years after the earthquake. Am J Trop Med Hyg 86: 5-6.

7. Smith W (2005) Tsunami in South Asia: What is the risk of post disaster infectious diseases outbreak? Ann Acad Med Singapore 34: 625-631.

8. Chen S, Loayza v, Querol R (2008) The aftermath of civil war, the world bank economic review 22: 63-85.

9. Puska P (2008) The North Kaleria Project: 30 years successfully preventing chronic diseases. Diabetes Voice 53(special use): 26-29.

10. Dembek ZF, Kortepeter MG, Pavlin JA (2007) Discernment between deliberate and natural infectious disease outbreaks. Epidemiol Infect 135: 353-371.

11. Clauw D, Jones E, Sharpe M, Wesseley S, Engel CC, et al. (2003) Unexplained symptoms after terrorism and war: An expert consensus statement. JOEM 45: 1040-1048.

12. Kloos H (1992) Health impacts of war in Ethiopia. Disasters 16:347-354.

13. Hendrix M (2012) Water in Ethiopia: Drought, disease and death. Global Majority E-Journal 3: 110-120.

14. Castero de M, Singer B (2003) Migration, urbanization and malaria: A Comparative Analysis of Dar es Salaam,Tanzania and Machadinho, Rondônia, Brazil. Conference on African Migration in Comparative Perspective, Johannesburg, South Africa.

15. Toole MJ, Waldman RJ (1997) The Public health aspects of complex emergencies and refugee situations. Annu Rev Public Health 18:283-312.

16. Mogne-Maillon M, Jimenez C, Norman C (2009) Imported infectious diseases in mobile populations in Spain. Emerg Infect Dis 15: 1745-1752. 